\title{
ACTIVATION OF INNOVATIVE ENTREPRENEURSHIP DEVELOPMENT
}

\author{
Olena Krylova', Kostiantyn Shaposhnykov ${ }^{2}$
}

\begin{abstract}
The purpose of the article is to develop proposals for intensifying the development of innovative entrepreneurship in Ukraine. The importance of intensifying innovative entrepreneurship is recognized by any business entity, because new innovative ideas, solutions embodied in a particular product can provide competitive advantages. The presence of entrepreneurial initiative by business entities, the use of effective tools to stimulate innovation, creativity and effectiveness of innovation can significantly enhance innovation entrepreneurship and overall efficiency of the innovation process. The methodological basis of this work is the synthesis of general scientific methods of theoretical and empirical research (method of cognition, analysis and synthesis, generalization and systematization of information). Results. Innovative entrepreneurship covers all stages of the innovation cycle: from the initiation of a new idea to obtaining specific results from the market use of the product. The main subjects of innovative entrepreneurship can be any enterprises and organizations that carry out innovative activities or are innovatively active. To develop effective measures to intensify innovative entrepreneurship, first of all, it is advisable to focus on identifying the strengths and weaknesses of innovative entrepreneurship, as well as opportunities and threats for its intensification in Ukraine. In this sense, it is important to assess the current level of innovation process, its staffing and financial resources, the level of innovation infrastructure, the establishment of integration relations between the main participants in the innovation process, the effectiveness of innovation, demand for innovative products and more. Practical implications. The analysis allowed us to reveal certain results. The strengths of the possible activation of the innovative enterprise include: the presence of a high level of personnel component of scientific potential, which characterizes the ability to generate new ideas; accumulated experience of successful innovation, cooperation between science and business, as evidenced by the main indicators of innovation, the number of innovationactive enterprises and enterprises in industry that implement innovations. Weaknesses for the intensification of innovative entrepreneurship should be highlighted: insufficient funding for science and education; declining trends in almost all performance indicators of innovation, which requires rapid implementation of measures to curb their further development in the field of innovation. Thus, in order to intensify innovative entrepreneurship in the near future, it is advisable to implement a number of measures, the tasks of which cover the following main areas of change: clear awareness of the national economy's ability to innovate, create conditions for new products, increase its competitiveness; ensuring diversification of sources of financing of innovative activity of enterprises in order to reduce the costs of acquisition and use of innovative products; establishing close and productive interaction of the main participants of innovative entrepreneurship. Value/originality. The use of comprehensive analysis allows to identify the main problems of hidden entrepreneurship, taking into account the specifics of its manifestation in modern conditions.
\end{abstract}

Key words: innovative entrepreneurship, innovative ideas, participants in the innovation process, innovative products, cooperation between science and business

Jel Classification: O32, O38, P21

\footnotetext{
Corresponding author:

${ }^{1}$ Black Sea Research Institute of Economics and Innovation, Odesa, Ukraine.

E-mail: Olena.Krylova.O@gmail.com

ORCID: https://orcid.org/0000-0001-9700-7302

${ }^{2}$ Black Sea Research Institute of Economy and Innovation, Odesa, Ukraine.

E-mail: k.s.shaposhnykov@gmail.com

ORCID: https://orcid.org/0000-0003-0640-9934
} 


\section{Introduction}

The importance of intensifying innovative entrepreneurship is recognized by any business entity, because new innovative ideas, solutions embodied in a particular product can provide competitive advantages. However, the active development of innovative entrepreneurship in Ukraine is hampered by a number of environmental factors, which affects both the total number of businesses that implement innovations and the effectiveness of their innovation activities. Among the important factors hindering the development of innovative entrepreneurship, first of all, it is worth noting the low consumer demand for innovative products, insufficient funding for scientific and technological development of the national economy; limited venture financing instruments; imperfection of motivation for active innovation. The presence of entrepreneurial initiative by business entities, the use of effective tools to stimulate innovation, creativity and effectiveness of innovation can significantly enhance innovation entrepreneurship and overall efficiency of the innovation process. World experience proves that an essential aspect of the intensification of innovative entrepreneurship is considered to be the rapprochement between the participants in the innovation process in the direction of increasing motivation in the creation and use of innovations. The implementation of such mutually beneficial cooperation between the participants will accelerate the technological renewal of enterprises, ensure the recovery of industry and the creation of new high-tech industries at the national level.

\section{Innovative entrepreneurship concept}

A significant amount of scientific research is devoted to the issues of intensification of innovation processes, effectiveness of innovation activities, development of innovative entrepreneurship. At the same time, the dynamism of the external environment, its complexity and unpredictability cause obstacles, new challenges for the development of innovation processes, which requires constant improvement of existing mechanisms, search and timely use of new opportunities and effective tools to stimulate innovative entrepreneurship. In particular, in Ukraine there are conducted thorough works on commercialization of results of innovative activity, directions of stimulation of activity in the field of innovations, systematization of the basic tools of activization of innovative business, financial aspects of support of development of innovative business and introduction of tax incentives in this sphere in modern conditions (Melnyk, 2014; Pavlenko, 2007; Lyakh, Lyashenko, Kuzmenko, 2018; Ivchenkova, 2018, etc.).Selection of previously unsolved parts of the overall problem. Despite the significant number of publications on the intensification of innovative entrepreneurship, they are more concerned with the development of small and medium-sized businesses in the field of creation and dissemination of innovations. At the same time, any enterprise is characterized by an understanding of innovative entrepreneurship as a permanent flow of innovative solutions, and therefore the issues of intensification of such activities in the economy of Ukraine and increase its effectiveness require in-depth attention. Such areas of further research are the identification of factors that prevent the activation of the effectiveness of innovative activities of enterprises and the development of a set of measures to find opportunities to eliminate the main obstacles to the development of innovative business. The purpose of the article is to develop proposals for intensifying the development of innovative entrepreneurship in Ukraine.

\section{Parameters of development of innovative entrepreneurship in Ukraine}

In the most general sense, innovative entrepreneurship is an activity that focuses on the application of new approaches, raw materials, ideas, products to meet consumer demand. Innovative entrepreneurship covers all stages of the innovation cycle: from the initiation of a new idea to obtaining specific results from the market use of the product. The main subjects of innovative entrepreneurship can be any enterprises and organizations that carry out innovative activities or are innovatively active. Innovative activity of enterprises must have certain characteristics:

- high level of flexibility, which allows to ensure constant product renewal and withstand competition;

- creativity, which allows to provide a constant flow of new ideas for fundamentally new products and processes;

- speed of response to the transformation in the needs of consumers;

- high motivation for innovation, independence in decision-making. 
To develop effective measures to intensify innovative entrepreneurship, first of all, it is advisable to focus on identifying the strengths and weaknesses of innovative entrepreneurship, as well as opportunities and threats for its intensification in Ukraine. In this sense, it is important to assess the current level of innovation process, its staffing and financial resources, the level of innovation infrastructure, the establishment of integration relations between the main participants in the innovation process, the effectiveness of innovation, demand for innovative products and more. The state of affairs with the innovation processes of individual countries and regions of the world as a whole is provided by rating assessments comparing the countries of recognized international institutions. Ukraine is represented in several international rankings that assess innovation potential, technological and innovative competitiveness.

The most common for assessing innovation processes are the following international rankings: Global Innovation Index, Bloomberg Innovation Index, Global Competitiveness Index, Innovation Index European Innovation Scoreboard (Innovation Union), Global Talent Competitiveness Index, Readiness for the Future of Production Assessment. The Global Innovation Index is generally considered to be one of the indicators of an objective assessment of the success of the world's innovation policy. The leaders of this index are mainly highly developed countries with high per capita income. According to the ratings by groups of human capital indicators (share of highly qualified specialists in the general structure of employment), research (cooperation of universities with business), protection of intellectual property rights (quantitative indicators on patents, as well as quantitative and qualitative parameters of scientific and technical activity issues) strong positions are held by the EU countries (Khaustov, 2018).

In particular, the leaders of this index in 2017 were fifteen European countries. China has been in the top 25 of the global innovation index since 2016 . These ratings assess not only the current state of affairs, but also partially characterize the possibilities of intensifying innovative entrepreneurship in the country, as well as the effectiveness of innovative activities of major economic entities.

According to the Global Innovation Index, human capital, knowledge and research results are still the main competitive advantage of Ukraine. However, even these benefits are gradually being lost. Thus, in 2018, compared to 2017, according to the subindex "Human Capital and Research", Ukraine moved to 43rd place with a loss of 2 positions. The reason for this situation was the reduction of education expenditures in\% of GDP (26th place in 2018 compared to $22 \mathrm{nd}$ in 2017) and research and development expenditures in\% of GDP (62nd place and 54th place, respectively).

The general state of innovation activity, which determines the prospects for the implementation of innovation processes and motivation for innovative entrepreneurship can be tracked by a number of basic indicators, which are presented in Table 1.

The analysis of the main indicators allows us to make some significant generalizations about the possibilities of intensifying innovative entrepreneurship: The dynamics of the number of innovatively active industrial enterprises over the last 19 years is characterized by insignificant fluctuations (about 1-2\%). On average, the share of such enterprises is about $16 \%$ of the total number of industrial enterprises. A similar trend is characteristic of the dynamics of the share of enterprises that have implemented innovations. On average, the fluctuations between annual indicators are $2-3 \%$. At the same time, in some periods the enterprises show annual growth (2010-2013, 2014-2016). However, for the share of innovatively active enterprises and for enterprises implementing innovations, 2019 was marked by a decrease of almost $2 \%$ compared to $3 \%$ in 2018 . The growth almost doubled in 2019 compared to 2018, which is characterized by a change in the share of innovative products (goods, services) ) sold in the total sales of c enterprises. But compared to 2010, there is a significant decline (almost 3 times) (see Table 1 ).

According to the State Statistics Service of Ukraine, the share of scientific and technical work performed in GDP for 2010-2019 decreased significantly (from $0.91 \%$ to $0.43 \%$ ). The share of scientific, scientific and technical works at the expense of the state budget also decreased by $0.12 \%$ percent of GDP in 2019 compared to $0.34 \%$ in 2010 (see Table 1).

In 2010-2019, expenditures on education and science decreased significantly. Thus, expenditures on science decreased from $0.8 \%$ of GDP to $0.2 \%$, on education - from $6.4 \%$ to $4.3 \%$ of GDP. Despite slight fluctuations, the number of specialists performing scientific and technical work is also reduced to the number of employed population (per 1,000 people). Thus, during 2010-2019, this 
Table 1

Indicators that characterize the ability to intensify innovative entrepreneurship

\begin{tabular}{|l|c|c|c|c|c|c|c|c|c|c|}
\hline \multicolumn{1}{|c|}{ Indicators } & 2010 & 2011 & 2012 & 2013 & 2014 & 2015 & 2016 & 2017 & 2018 & 2019 \\
\hline \multicolumn{1}{|c|}{1} & 2 & 3 & 4 & 5 & 6 & 7 & 8 & 9 & 10 & 11 \\
\hline The degree of depreciation of fixed assets of industry,\% & 74.9 & 75.9 & 76.7 & 77.3 & 83.5 & 60.1 & 58.1 & 55.1 & 60.6 & 56.9 \\
\hline $\begin{array}{l}\text { The share of the volume of performed scientific and } \\
\text { scientific-technical works in GDP, \% }\end{array}$ & 0.91 & 0.80 & 0.80 & 0.80 & 0.69 & 0.63 & 0.48 & 0.45 & 0.47 & 0.43 \\
\hline $\begin{array}{l}\text { The amount of expenditures for scientific and scientific- } \\
\text { technical work at the expense of the state budget, \% of GDP }\end{array}$ & 0.34 & 0.30 & 0.34 & 0.33 & 0.26 & 0.20 & 0.16 & 0.16 & 0.17 & 0.12 \\
\hline $\begin{array}{l}\text { The number of specialists who perform scientific and } \\
\text { technical work, to the number of employed population } \\
\text { (per 1 thousand people) }\end{array}$ & 4.4 & 4.2 & 4.0 & 4.0 & 3.8 & 3.9 & 3.9 & 3.7 & 3.5 & 3.7 \\
\hline The expenditure on science, \% of GDP & 0.8 & 0.7 & 0.8 & 0.8 & 0.7 & 0.6 & 0.5 & 0.4 & 0.4 & 0.2 \\
\hline The expenditure on education, \% of GDP & 6.4 & 6.2 & 6.7 & 6.7 & 5.9 & 5.3 & 5.0 & 5.4 & 5.1 & 4.3 \\
\hline $\begin{array}{l}\text { The share of enterprises implementing innovations in the } \\
\text { total number of industrial enterprises, \% }\end{array}$ & 11.5 & 12.8 & 13.6 & 13.6 & 12.1 & 15.2 & 16.6 & 14.3 & 15.6 & 13.8 \\
\hline $\begin{array}{l}\text { Number of innovatively active industrial enterprises in\% } \\
\text { to the total number of industrial enterprises }\end{array}$ & 13.8 & 16.2 & 17.4 & 16.8 & 16.1 & 17.3 & 18.9 & 16.2 & 16.4 & 15.8 \\
\hline $\begin{array}{l}\text { Expenditures on innovations in\% to the total volume of } \\
\text { sold industrial products (goods, services) }\end{array}$ & 0.8 & 1.1 & 0.8 & 0.7 & 0.5 & 0.8 & 1.1 & 0.4 & 0.4 & 0.5 \\
\hline $\begin{array}{l}\text { The number of new technological processes introduced } \\
\text { into production, thousand units }\end{array}$ & 2.0 & 2.5 & 2.2 & 1.6 & 1.7 & 1.2 & 3.4 & 1.8 & 2.0 & 2.3 \\
\hline $\begin{array}{l}\text { Number of introduced types of innovative products } \\
\text { (goods, services), thousand units }\end{array}$ & 2.4 & 3.2 & 3.4 & 3.1 & 3.7 & 3.1 & 4.1 & 2.4 & 3.8 & 2.2 \\
\hline $\begin{array}{l}\text { The share of the volume of sold innovative products } \\
\text { (goods, services) in the total volume of sold products } \\
\text { (goods, services) of industrial enterprises, \% }\end{array}$ & 3.8 & 3.8 & 3.3 & 3.3 & 2.5 & 1.4 & 0.9 & 0.7 & 0.8 & 1.3 \\
\hline $\begin{array}{l}\text { Received security documents, thousand units } \\
\text { International registration of industrial property, units }\end{array}$ & 484 & 552 & 498 & 677 & 594 & 622 & 623 & 565 & 506 & 657 \\
\hline
\end{tabular}

Source: compiled according to official statistics

reduction amounted to $0.7 \%$. Relative stability is characteristic of the dynamics of innovation costs in $\%$ to the total volume of sold industrial products (goods, services). During the period 2010-2019, a significant reduction was observed only in 2016-2018 from $1.1 \%$ to $0.4 \%$.

The growth of international registration of industrial property objects should be considered as a positive characteristic. Thus, in 2019, this figure increased to 657 units compared to 484 units in 2010. At the same time, the number of received security documents was reduced. If in 2010 their number was 5.3 thousand units, in 2019 it is already 3.85 thousand units.

Thus, summing up the prospects for intensification of innovative entrepreneurship, we can highlight the following:

- the strengths of the possible activation of the innovative enterprise include: the presence of a high level of human resources component in scientific potential, which characterizes the ability to generate new ideas; accumulated experience of successful innovation, cooperation between science and business, as evidenced by the main indicators of innovation, the number of innovationactive enterprises and enterprises in industry that implement innovations;

- weaknesses for the intensification of innovative entrepreneurshipshould behighlighted: insufficient funding for science and education, declining trends in almost all performance indicators of innovation, which requires rapid implementation of measures to curb their further development in the field of innovation; insignificant performance indicators for security documents;

- opportunities for activating an innovative enterprise: stimulating the introduction of innovations in industrial enterprises will allow to intensify the creation of new technologies and new innovative products; improving the efficiency of the use of existing research and innovation potential; diversification of sources of financing of innovative activity due to active introduction of startups, distribution of world experience of 
creation of business universities that will promote convergence of education with business; improving the regulatory and legal support of innovative entrepreneurship through measures to stimulate demand for innovation by business; raising the general level of innovative business culture and development of innovative entrepreneurship through access to the EU financial programs;

- among the main threats to be addressed should be identified: financial and administrative barriers that hinder the development of innovative business; insufficient sources of funding for innovation due to high interest rates on loans; insufficient development of innovation infrastructure; the difficulty of training and selecting skilled workers to produce innovative ideas; lack of motivation among young people to innovate; imperfection and complexity of procedures for obtaining security documents for intellectual property.

Thus, systematizing the results, it is advisable to focus on the need to implement the following areas of activation of innovative entrepreneurship in Ukraine (Figure 1).
Block 1. Ensuring the development of innovation infrastructure. The main objectives of this block of measures are to overcome barriers that hinder the development of infrastructure to support innovative entrepreneurship:

- formation of objects of innovation infrastructure at the local level;

- creation of a network of business incubators, strategic centers, technology parks, including higher education institutions;

- formation of databases of innovative ideas that should be available to entrepreneurs and other stakeholders;

- providing consulting support for the protection of intellectual property, creating startups, advising on the process of commercialization, marketing innovations.

Block 2. Increasing the volume of innovative products and ensuring the export of hightech products. The tasks of this group include measures related to increasing the production of innovative products and the share of high-tech exports:

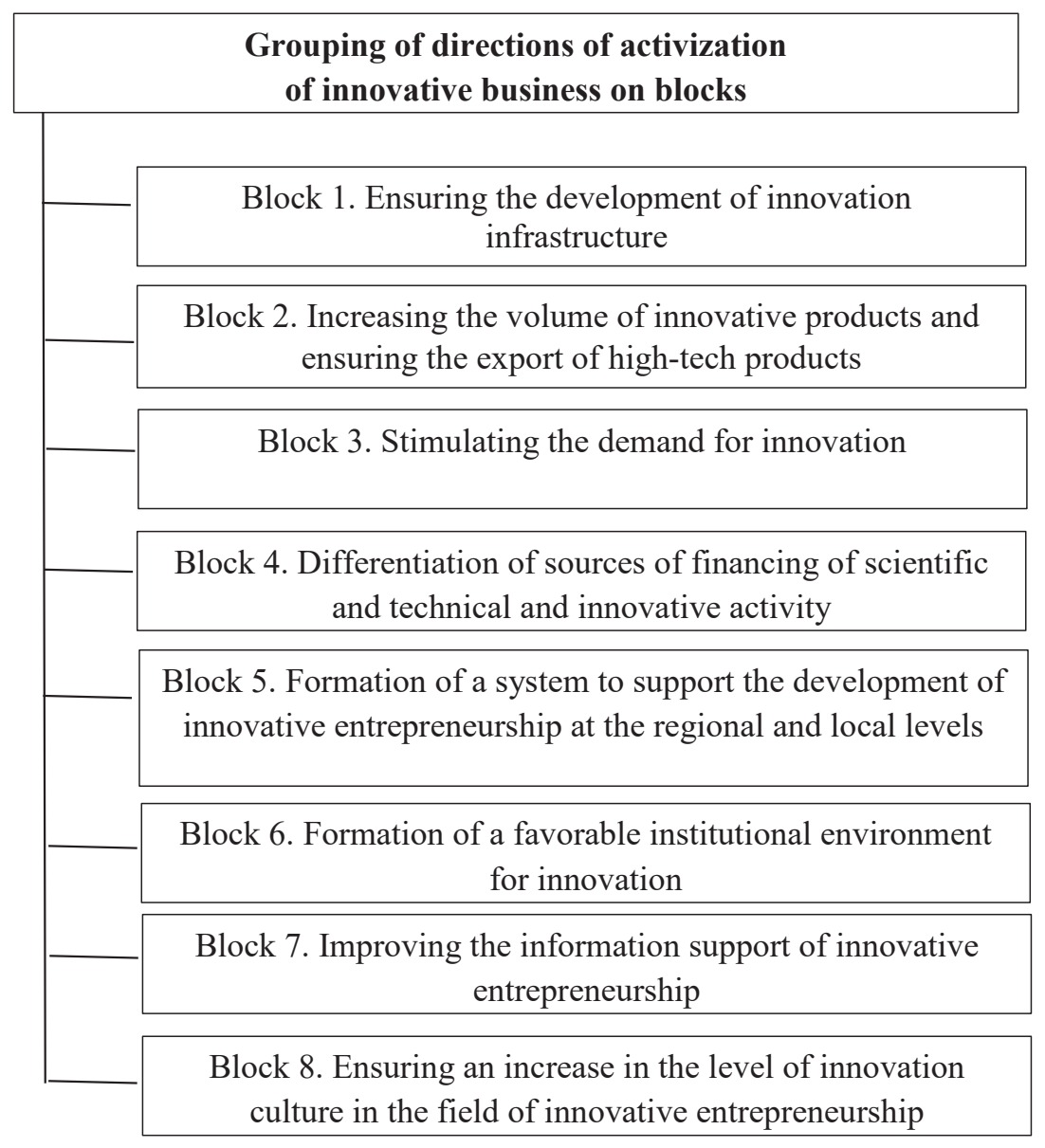

Figure 1. Directions for activating innovative entrepreneurship 
- monitoring of technology development and application of forecasting at macro and micro levels; - identification of opportunities for technology production in Ukraine;

- active introduction of technology transfer;

- development of import substitution programs for innovative products;

- stimulating the export of high-tech products.

Block 3. Stimulating the demand for innovation. The tasks of this group are to overcome obstacles on the part of governmental and departmental structures in stimulating the demand for innovation: - introduction of benefits for companies that manufacture innovative products;

- introduction of incentives for enterprises that buy innovative products;

- use of the mechanism of public procurement for innovative products;

- establishment of preferential tax conditions and application of preferences for companies that produce innovative products;

- use of compensation of expenses to entrepreneurs, starting from the first three years of operation of the business incubator $(60 \%, 40 \%$ and $20 \%$, respectively).

Block 4. Differentiation of sources of financing of scientific and technical and innovative activity. Within the framework of the tasks of this block, it is envisaged to overcome barriers that cause restrictions on budget expenditures for scientific and technical activities and the use of innovations:

- development, improvement and implementation of regulatory and legal support for the functioning of venture funds, mutual investment institutions in the field of innovation;

- consulting support for fundraising, access to programs to support the development of innovation, international grant programs in the field of innovation;

- application of the mechanism of tax holidays for subjects of innovative entrepreneurship;

- expansion of the list of high-tech critical imports of equipment and technologies, without collection of import duties;

- state guarantee and subsidization of interest payments on loans issued for export contracts of technologies and innovative products.

Block 5. Formation of a system to support the development of innovative entrepreneurship at the regional and local levels. The tasks of this group are focused on overcoming obstacles to the effectiveness of the system of support for innovative entrepreneurship at the regional and local levels: - provision of financial, informational, educational support at the expense of local budgets on the basis of creation of special funds to support innovative entrepreneurship.

Block 6. Formation of a favorable institutional environment for innovation. This group contains tasks, the implementation of which overcomes obstacles to comprehensive legislative support for the development of innovative entrepreneurship: - development of a national strategy for the development of innovative entrepreneurship until 2030;

- digitalization of administrative support of enterprises, in particular the widespread use of a "single window" technology;

- advanced training of administrative staff through seminars, trainings, courses, round tables, etc.;

- overcoming psychological barriers;

- introduction of administrative liability for delays in making decisions on the implementation of innovations;

- involvement of professionals at all stages of implementation of innovative projects;

- creation of a unified system of training and advanced training in the field of technological innovation, including distance learning;

- development of a network of "innovative business activities" to form a database of contacts to establish new contacts between entrepreneurs, experts and solve their problems and establish effective cooperation in the field of innovation.

Block 7. Improving the information support of innovative entrepreneurship. Within this group there are tasks to overcome barriers associated with lack of awareness of innovative entrepreneurs:

- provision of free consulting services;

- providing innovative entrepreneurs with a continuous exchange of information, ensuring its availability and reliability;

- formation and development of a system of information and consulting support for innovative entrepreneurship at the national level.

Block 8. Ensuring an increase in the level of innovation culture in the field of innovative entrepreneurship. This group envisages the implementation of tasks to overcome barriers associated with the insufficient level of innovation culture in the field of innovative entrepreneurship: - formation of a positive image of an innovative entrepreneur on the basis of popularization of 
innovative ideas, creative thinking among the population;

- increasing the social responsibility of business.

Thus, the results of the study indicate the need to solve a number of problems for the development of innovative entrepreneurship in Ukraine in modern business conditions.

\section{Conclusions}

Innovative entrepreneurship is a dynamic form of innovative activity that provides a continuous flow of innovative ideas and their practical implementation in specific innovative products. To intensify innovative entrepreneurship in the near future, it is advisable to implement a number of measures, the tasks of which cover the following main areas of change: a clear understanding of the national economy's ability to innovate, create conditions for new products, increase its competitiveness; ensuring diversification of sources of financing of innovative activity of enterprises in order to reduce the costs of acquisition and use of innovative products; establishing close and productive interaction of the main participants of innovative entrepreneurship.

\section{References:}

Innovative Ukraine 2020: national report (2015) / for general. ed. V.M. Heitz and others; NAS of Ukraine. Kyiv, 336 p. (in Ukrainian)

Melnyk, O. S. (2014). State and problems of development of innovative entrepreneurship and scientific and technical activity / The first stage of modernization of the economy of Ukraine: experience and problems / for general ed. V.I. Liashenko; NAS of Ukraine, Institute of Industrial Economics; Classic private university. Zaporizhzhia: Classical Private University, 798 p. (in Ukrainian)

Pavlenko, I. A. (2007). Innovative entrepreneurship in the transformational economy of Ukraine: monograph. Kyiv: KNEU, 248 p. (in Ukrainian)

Lyakh, O. V., Lyashenko, V. I., \& Kuzmenko, N. V. (2018). The concept of institutional support for inclusive entrepreneurship at the regional level. Economic Bulletin of Donbass, no. 2(52), pp. 212-232. (in Ukrainian)

Ivchenkova, O. Y., \& Krykunenko, K. M. (2018). Innovative entrepreneurship as a component of the strategy of economic development of Ukraine. Economic Bulletin of Donbass, no. 3(53), pp. 141-146. (in Ukrainian)

Khaustov, V. K. (2018). Innovative dimension of Ukraine's course towards European integration. Economics and forecasting, no. 2, pp. 135-150. (in Ukrainian)

State Statistics Service of Ukraine (2020). URL: http://www.ukrstat.gov.ua/ (accessed: 23.01.2020).

Statistics, reports, plans. State Enterprise "Ukrainian Institute of Intellectual Property" (Ukrpatent). URL: https://ukrpatent.org/en/articles/statistics (accessed: 29.01.2020).

Education Statistics. Available Indicators. The World Bank. URL: http://datatopics.worldbank.org/ education/indicators (accessed: 29.01.2020).

OECD Statistics. URL: https://stats.oecd.org/Index.aspx (accessed: 28.01.2020).

Ministry of Finance of Ukraine. URL: https://index.minfin.com.ua/ua/ (accessed: 28.01.2020).

Denisyuk, V. A. (2006). Commercialization of research results: problems and prospects. Bulletin of the NAS of Ukraine, no. 5, pp. 39-53.

Lukashina, M. V. (2009). Strategic directions of development of innovative entrepreneurship. Economics of forecasting, no. 8, pp. 86-98. 